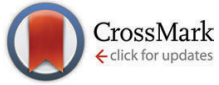

Cite this: Phys. Chem. Chem. Phys., 2014, 16, 25969

\title{
Spectroscopic characterization of the interaction of lithium with thin films of the ionic liquid 1-octyl-3-methylimidazolium bis(trifluoromethylsulfonyl)amide $\dagger$
}

\author{
Mark Olschewski, ${ }^{a}$ René Gustus, ${ }^{a}$ Marcel Marschewski, ${ }^{b}$ Oliver Höfft*a and \\ Frank Endres*a
}

\begin{abstract}
In this experimental investigation the interaction of lithium with 1-octyl-3-methylimidazolium bis(trifluoromethylsulfonyl)amide $\left([\mathrm{OM} / \mathrm{m}] \mathrm{Tf}_{2} \mathrm{~N}\right)$ is shown. For this purpose thin films of lithium and $[\mathrm{OM} / \mathrm{m}] \mathrm{Tf}_{2} \mathrm{~N}$ were successively vapor deposited on a copper substrate and analyzed by X-ray Photoelectron Spectroscopy (XPS) as well as by Ultraviolet Photoelectron Spectroscopy (UPS). When [OMIm] Tf ${ }_{2} \mathrm{~N}$ is evaporated on top of a thin lithium film a chemical shift analysis of XPS spectra shows a variety of reaction products like $\mathrm{LiF}, \mathrm{Li}_{2} \mathrm{O}$ and $\mathrm{Li}_{x} \mathrm{CH}_{y}$ which reveals the instability of the $\mathrm{IL}$ against lithium. Time resolved XPS spectra were discussed to distinguish cation reactions from beam damage effects. In a second step lithium is deposited on a [OMIm] Tf ${ }_{2} \mathrm{~N}$ layer. The XPS spectra are in agreement with the results of the previous step, but show some differences concerning the [OMIm] cation. In a third step [OMIm] $T_{2} \mathrm{~N}$ has been deposited on a passivated lithium layer. XPS results show nearly unaffected $\left[\mathrm{Tf}_{2} \mathrm{~N}\right]^{-}$anions and partially decomposed $[\mathrm{OMlm}]^{+}$cations. Interestingly the cation reactions show similarities when compared to the interaction of $\left[\mathrm{C}_{4} \mathrm{C}_{1}\right.$ Pyrr] $\mathrm{Tf}_{2} \mathrm{~N}$ (1-butyl-1-methylpyrrolidinium bis[trifluoromethylsulfonyl]amide) and lithium.
\end{abstract}

Received 14th July 2014, Accepted 22nd October 2014

DOI: $10.1039 / c 4 c p 03091 e$

www.rsc.org/pccp

\section{Introduction}

Room-temperature ionic liquids (RT-ILs) are of fundamental interest as organic solvents and functionalized materials, as they have a couple of impressive chemical and physical properties. ${ }^{1-3}$ Due to their quite low vapor pressure at room temperature, they can be analyzed under vacuum conditions enabling a variety of surface sensitive analysis methods. ${ }^{4-6}$ As RT-ILs exhibit good ion conductivities, high temperature stability and a large electrochemical window together with a good solubility for lithium salts, they are of potential interest as electrolyte for non flammable Li based batteries, ${ }^{7-9}$ like e.g. lithium/air batteries.

Lithium ion batteries are preferentially used for energy storage in cell phones, laptop computers and nowadays in some electrically powered cars. As their energy density is only $\sim 150 \mathrm{~W} \mathrm{~h} \mathrm{~kg}^{-1}$ and as LiPo batteries are flammable, further development is needed.

Especially fires of lithium ion batteries in e-cars recently attracted the public interest as the commonly used organic

\footnotetext{
${ }^{a}$ Institute of Electrochemistry, Clausthal University of Technology, Arnold-Sommerfeld-Str 6, D-38678 Clausthal-Zellerfeld, Germany. E-mail: frank.endres@tu-clausthal.de, o.hoefft@pe.tu-clausthal.de

${ }^{b}$ Institut für Energieforschung und Physikalische Technologien, Technische Universität Clausthal, Leibnizstrasse 4, D-38678 Clausthal-Zellerfeld, Germany $\dagger$ Electronic supplementary information (ESI) available. See DOI: 10.1039/ c4cp03091e
}

solvents for the cells are also volatile and flammable, implying some danger for the driver and rescuers in the case of an accident. Furthermore organic solvents are reactive against metallic lithium, thus lithium anodes, which would enable even higher energy densities, ${ }^{10,11}$ are practically excluded with conventional electrolytes.

The variety of possible combinations of anions and cations allows modifying the electrolyte properties precisely. Replacing the organic solvents by ionic liquids has been widely tested and promises to be a good compromise between performance, safety and stability. ${ }^{12-14}$

The interaction of lithium with organic solvents for battery applications like tetrahydrofuran (THF) and propylene carbonate (PC) has been done for instance by Zhuang et al. ${ }^{15}$ They evaporated thin films of THF and PC in a UHV chamber on a lithium layer and observed a lithium induced decomposition of the organic molecules by using photoelectron spectroscopy (XPS). In the present paper the stability of 1-octyl-3-methylimidazolium bis(trifluoromethylsulfonyl)amide ([OMIm] $\left.\mathrm{Tf}_{2} \mathrm{~N}\right)$ against lithium has been investigated by vapor depositing a thin film of the RT-IL on top of a lithium covered copper substrate. The interactions have been analyzed by photoelectron spectroscopy using $\mathrm{Al} \mathrm{K}_{\alpha}$ radiation to observe elemental composition as well as chemical state information and $\mathrm{He}$ I radiation for valence band spectra of the sample. 
In a second step lithium has been deposited on a [OMIm] $\mathrm{Tf}_{2} \mathrm{~N}$ layer as this might change reaction kinetics or even show differences based on the formation of passivating layers of the reaction products. Beyond that $[\mathrm{OMIm}] \mathrm{Tf}_{2} \mathrm{~N}$ is deposited on a previously oxidized lithium layer in a third step.

As Keppler et al. observed degradation of [EMIm] $\mathrm{Tf}_{2} \mathrm{~N}$ during non monochromatic X-ray irradiation ${ }^{16}$ it is important to distinguish beam damage related effects in the interaction of lithium and [OMIm] $\mathrm{Tf}_{2} \mathrm{~N}$ from those occurring immediately after deposition. Therefore the measurements were evaluated with respect to the irradiation time.

\section{Experimental}

The experimental investigations as well as the preparation steps were performed in an UHV chamber with a base pressure of below $5 \times 10^{-10}$ mbar. A polished copper foil, commonly used as current collector in battery applications, ${ }^{17}$ was used as substrate, fixed on a molybdenum sample holder and transferred into the UHV chamber.

For each of the experiments the substrate was cleaned referring to the literature: ${ }^{18}$ it was heated by a resistive sample heater (PBN) as part of the Omicron manipulator to $880 \mathrm{~K}$ for 10 minutes and etched at this temperature for 10 minutes by argon ions with a kinetic energy of $2 \mathrm{keV}$ using an Omicron ISE 5 ion source. Afterwards, it was heated to $930 \mathrm{~K}$ for 15 to 20 minutes, depending on the base pressure in the main chamber. The purity of the copper surface was verified by XPS survey spectra (see ESI $\dagger$ ).

The ionic liquid 1-octyl-3-methylimidazolium bis(trifluoromethylsulfonyl)amide ([OMIm] $\left.\mathrm{Tf}_{2} \mathrm{~N}\right)$ was purchased in the highest available quality (NMR: purity $>99 \%$, IC: Halides $<100 \mathrm{ppm}$ ) from Io-Li-Tec (Germany) and dried under vacuum conditions at $375 \mathrm{~K}$ to remove the water content to below $2 \mathrm{ppm}$.

To produce a thin layer of $[\mathrm{OMIm}] \mathrm{Tf}_{2} \mathrm{~N}$, the RT-IL was evaporated at $415 \mathrm{~K}$ for 600 seconds using the TCE-BSC (Kentax GmbH) evaporator resulting in a layer thickness of about $7 \mathrm{~nm}$ on top of the substrate, which was validated by XPS intensity loss of the $\mathrm{Cu}$ $2 \mathrm{p}_{3 / 2}$ peak after deposition. Evaporation of [OMIm] $\operatorname{Tf}_{2} \mathrm{~N}$ in thin films on $\mathrm{Au}(111)$ under UHV conditions has been well investigated. ${ }^{19,20}$ The ionic liquid remains intact as thermal decomposition first can be observed in a temperature range above $600 \mathrm{~K}^{21}$

For lithium evaporation a lithium-metal alloy (Alvasources ${ }^{\circledR}$ AS-3-Li-10-C by Alvatec) was heated via resistive heating with a current of 8 A resulting in a temperature of about $875 \mathrm{~K}$. At this temperature pure lithium is emitted from the alloy, which is stored in a stainless steel tube. Lithium was vapor deposited for 180 seconds in all experiments described here. The amount of lithium can be estimated by evaporating lithium on the substrate and calculating the thickness by XPS measurements with approx. $0.6 \mathrm{~nm}$. As we expect a difference in the interaction of lithium with the ionic liquid when lithium is previously deposited on the substrate and followed by evaporation of $[\mathrm{OMIm}] \mathrm{Tf}_{2} \mathrm{~N}$ compared to the opposite procedure, this investigation includes three experimental steps:

(1) Depositing $[\mathrm{OMIm}] \mathrm{Tf}_{2} \mathrm{~N}$ on a layer of $\mathrm{Li}$
(2) Depositing Li on a layer of $[\mathrm{OMIm}] \mathrm{Tf}_{2} \mathrm{~N}$

(3) Depositing [OMIm] $\mathrm{Tf}_{2} \mathrm{~N}$ on a layer of previously oxidized lithium

The steps were characterized by valence band spectroscopy (UPS) using an He I VUV source (Omicron HIS 13) with $21.2 \mathrm{eV}$ photon energy and core level spectroscopy (XPS) using Al $\mathrm{K}_{\alpha}$ radiation with $1486.6 \mathrm{eV}$ photon energy of a non monochromatic X-ray source (Omicron DAR 400).

While the sample is grounded for the XPS measurements, a potential of $5 \mathrm{~V}$ was applied for the UPS experiments supporting the emission of low energy electrons. Electrons emitted were detected by a hemispherical analyzer (Omicron EA125) under an angle of $45^{\circ}$ to the surface normal.

Since degradation of ionic liquids with imidazolium cations, that are exposed to non-monochromatic X-ray radiation, was observed before, ${ }^{16}$ XPS analysis was performed as fast detail scan of the $\mathrm{C} 1 \mathrm{~s}, \mathrm{~N} 1 \mathrm{~s}, \mathrm{O} 1 \mathrm{~s}, \mathrm{~F} 1 \mathrm{~s}, \mathrm{~S} 2 \mathrm{p}$ and $\mathrm{Li} 1 \mathrm{~s}$ regions with a total exposure time of about $1 \mathrm{~h}$.

As X-ray degradation is a continuous process relative to the exposure time, the beam damage based reaction products can be emphasized by evaluating detail spectra time resolved. For the time resolved XPS plots a 5 data point wide moving average procedure has been applied to time and energy information of fast detail scans.

All spectra were displayed as a function of the binding energy with respect to the Fermi level. The XPS spectra have been charge corrected by fixing the $\mathrm{F} 1$ s component of the $\mathrm{CF}_{3}$ group at $688.5 \mathrm{eV}$ to improve comparability of the results.

For quantitative XPS analysis, a Shirley-background-subtraction was employed. ${ }^{22}$ Photoelectron peak areas were calculated by fitting Gauss-type profiles optimized by the Levenberg-Marquard algorithm with the CasaXPS software. Photoelectric cross-sections calculated by Scofield ${ }^{23}$ and asymmetry factors calculated by Yeh and Lindau ${ }^{24}$ as well as the transmission function of the hemispherical analyzer have been taken into account for stoichiometric calculations. The free mean path of the electrons in organic samples was also involved in the calculations, according to literature. ${ }^{25}$

\section{Results}

\section{Reference spectrum of $[\mathrm{OMIm}] \mathrm{Tf}_{2} \mathrm{~N}$ on $\mathrm{Cu}$}

In Fig. 1-5 detail XPS spectra of the $\mathrm{C} 1 \mathrm{~s}, \mathrm{~N} 1 \mathrm{~s}, \mathrm{~F}$ 1s and $\mathrm{O} 1 \mathrm{~s}$ regions are shown. For a better comparability the intensity of the different experimental parts is scaled equally in each figure. The binding energy (BE) and the relative amount of the fitted component peaks are displayed in Table 1 . As the signal/noise ratio of the $S 2$ p peak is rather bad, it has not been taken into account and thus is not displayed here. In the first row (a) of the figures the spectra for [OMIm] $\mathrm{Tf}_{2} \mathrm{~N}$ as deposited on the copper substrate are shown.

Due to the strong $\mathrm{C}-\mathrm{F}_{3}$ bond the $\mathrm{C} 1 \mathrm{~s}$ peak of the anion at $292.8 \mathrm{eV}$ is clearly distinguished from the cation peaks at $286.4 \mathrm{eV}$ and $284.8 \mathrm{eV}$. While the first cation component at $286.4 \mathrm{eV}$ is associated with carbon atoms in the imidazolium structure in a 


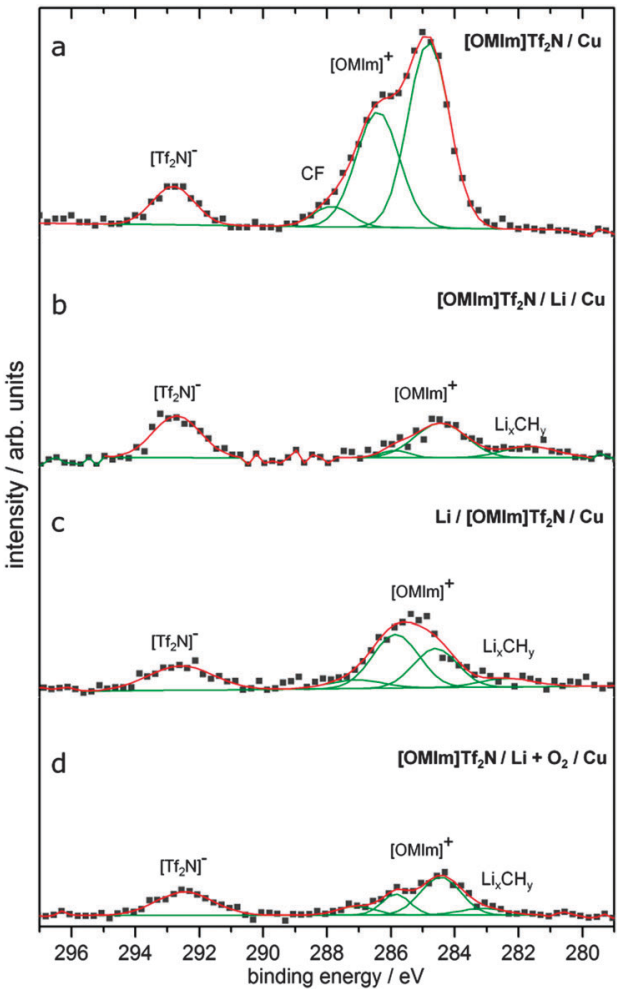

Fig. 1 C 1s XPS spectra for - (a) pure [OMIm]Tf $2 \mathrm{~N}$ on copper, (b) [OMIm]Tf $f_{2} \mathrm{~N}$ deposited on a lithium layer, (c) lithium deposited on a [OMIm]Tf $f_{2} \mathrm{~N}$ layer, (d) $[\mathrm{OMIm}] \mathrm{Tf}_{2} \mathrm{~N}$ deposited on $\mathrm{Li}_{2} \mathrm{O}$.

Table 1 XPS C 1s, N 1s, O 1s and F 1s binding energies and stoichiometry for pure $[\mathrm{OMIm}] \mathrm{Tf}_{2} \mathrm{~N}$ on copper, [OMIm] Tf ${ }_{2} \mathrm{~N}$ deposited on a lithium layer, lithium deposited on a $[\mathrm{OM} / \mathrm{m}] \mathrm{Tf}_{2} \mathrm{~N}$ layer, $[\mathrm{OM} / \mathrm{m}] \mathrm{Tf}_{2} \mathrm{~N}$ deposited on $\mathrm{Li}_{2} \mathrm{O}$

$[\mathrm{OMIm}] \mathrm{Tf}_{2} \mathrm{~N}[\mathrm{OMIm}] \mathrm{Tf} \mathrm{f}_{2} \mathrm{~N} / \mathrm{Li} \quad \mathrm{Li} /[\mathrm{OMIm}] \mathrm{Tf}_{2} \mathrm{~N}[\mathrm{OMIm}] \mathrm{Tf}_{2} \mathrm{~N} / \mathrm{Li}_{2} \mathrm{O}$

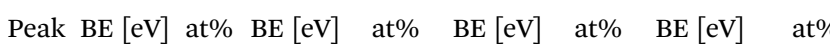

\begin{tabular}{lrrrrrrrr}
\hline C 1s & & & 281.7 & 13 & 282.4 & 7 & 283.1 & 8 \\
& 284.8 & 51 & 284.5 & 39 & 284.6 & 25 & 284.5 & 37 \\
& 286.4 & 33 & 285.9 & 4 & 285.9 & 37 & 285.9 & 15 \\
& 287.9 & 5 & & & 287.1 & 7 & 287.1 & 8 \\
& 292.8 & 11 & 292.7 & 43 & 292.6 & 24 & 292.5 & 32 \\
& & & & & & & & \\
N 1s & & & 397.4 & 73 & 397.3 & 66 & 397.4 & 49 \\
& 399.3 & 41 & 399.3 & 27 & 399.3 & 34 & 399.3 & 35 \\
& 401.8 & 59 & & & & & 401.0 & 16 \\
& & & & & & & & \\
O 1s & & & 528.1 & 16 & 528.5 & 28 & 528.1 & 25 \\
& 530.5 & 12 & & & & & 530.5 & 10 \\
& & & 531.2 & 16 & 531.2 & 31 & 531.2 & 17 \\
& 532.4 & 88 & 532.4 & 68 & 532.4 & 41 & 532.4 & 48 \\
& & & & & & & & \\
F 1s & & & 684.8 & 25 & 684.9 & 33 & 684.8 & 7 \\
& 688.5 & 100 & 688.5 & 75 & 688.5 & 67 & 688.5 & 93 \\
\hline
\end{tabular}

chemical environment of nitrogen the second component at $284.8 \mathrm{eV}$ is associated with the residual carbon in imidazolium and in the octyl-chain. ${ }^{26}$

The small peak at $287.9 \mathrm{eV}$ can be assigned to $\mathrm{C}-\mathrm{F}^{27}$ which may be associated with radiation induced decomposition of the anion.

The $\mathrm{N}$ 1s spectrum in Fig. 2a can as well be divided into two components, as the nitrogen in the cation is more positive

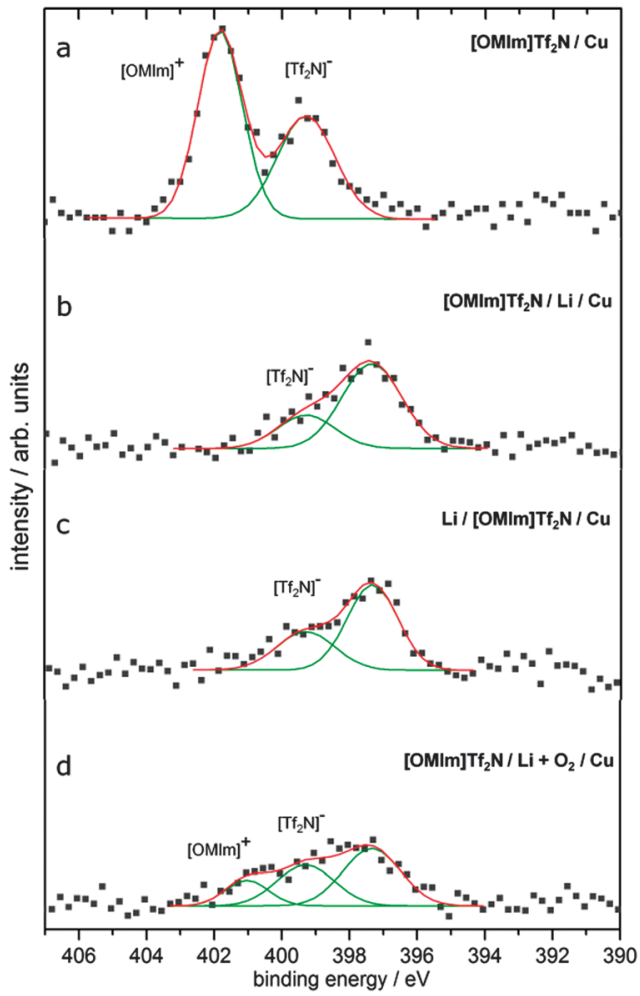

Fig. $2 \mathrm{~N}$ 1s XPS spectra for - (a) pure [OMIm] Tf $2 \mathrm{~N}$ on copper, (b) [OMIm] Tf ${ }_{2} \mathrm{~N}$ deposited on a lithium layer, (c) lithium deposited on a $\left[\mathrm{OMIm]} \mathrm{Tf}_{2} \mathrm{~N}\right.$ layer, (d) $[\mathrm{OM} / \mathrm{m}] \mathrm{Tf} \mathrm{f}_{2} \mathrm{~N}$ deposited on $\mathrm{Li}_{2} \mathrm{O}$.

compared to the nitrogen in the anion. The first peak at $401.8 \mathrm{eV}$ is related to the $[\mathrm{OMIm}]^{+}$cation while the second peak at $399.3 \mathrm{eV}$ nitrogen peak is related to $\left[\mathrm{Tf}_{2} \mathrm{~N}\right]^{-26}$.

The spectrum in Fig. 3a shows the $\mathrm{O} 1 \mathrm{~s}$ component of the anion peak of [OMIm] $\mathrm{Tf}_{2} \mathrm{~N}$ at $532.4 \mathrm{eV}$ next to a rather small peak at $530.5 \mathrm{eV}$. The small peak is a hint for oxidation of the copper substrate either by oxygen impurities during evaporation or by decomposed anions.

In Fig. $4 \mathrm{a}$ the XPS spectrum of the F 1s region is displayed. It consists of a single peak at $688.5 \mathrm{eV}$ that can be assigned to carbon in the $\mathrm{CF}_{3}$ component of the anion.

Due to the high reactivity of copper the interactions of RT-ILs with the copper substrate have to be well considered. Uhl et al. recently reported about changes of $\left[\mathrm{C}_{4} \mathrm{C}_{1}\right.$ Pyrr $] \mathrm{Tf}_{2} \mathrm{~N}$ (1-butyl-1methylpyrrolidinium bis[trifluoromethylsulfonyl]amide) vapor deposited in a sub-monolayer film on a $\mathrm{Cu}(111)$ surface at room temperature. ${ }^{28}$ They observed decomposition of the $\left[\mathrm{Tf}_{2} \mathrm{~N}\right]^{-}$ anion and found a stable adsorbate phase mainly containing $\mathrm{Cu}_{x} \mathrm{~S}$ but as well adsorbed $\mathrm{CF}_{3}$, while the cation remains intact.

Thus the $\mathrm{C}-\mathrm{F}$ assigned peak in the $\mathrm{C} 1 \mathrm{~s}$ spectrum and the small peak in the $\mathrm{O} 1 \mathrm{~s}$ spectrum might show radiation based anion decomposition ${ }^{16}$ but might as well be based on anion degradation in presence of the copper surface. However, as the present XPS results for [OMIm] $\mathrm{Tf}_{2} \mathrm{~N}$ on copper are in good agreement with XPS studies in the literature $e^{26,29-31}$ and as there are no further chemical changes visible, bulk interactions between $[\mathrm{OMIm}] \mathrm{Tf}_{2} \mathrm{~N}$ and copper can be neglected. 


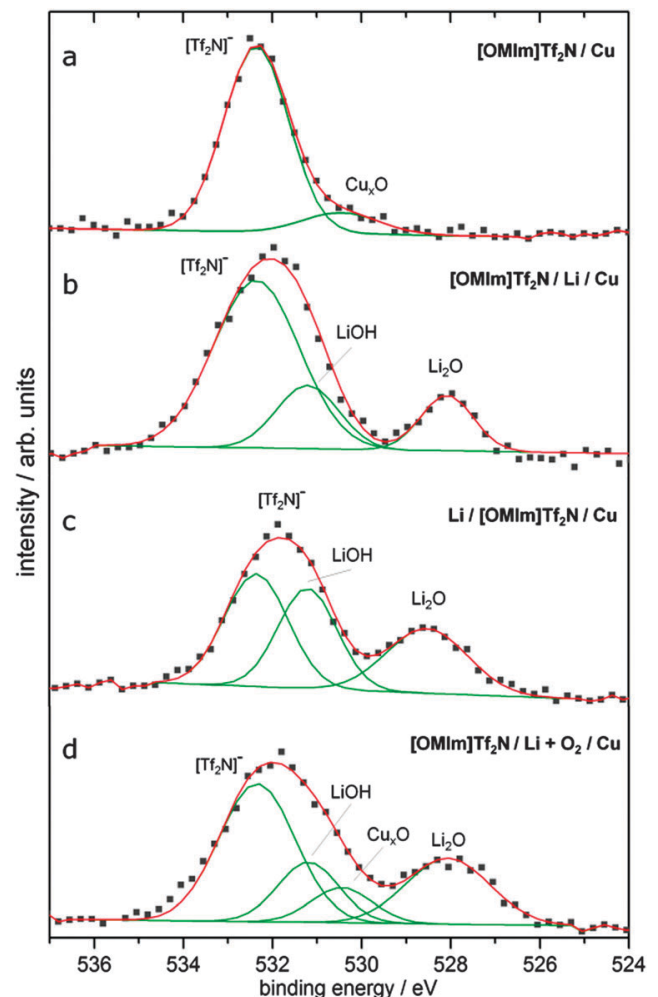

Fig. 3 O 1s XPS spectra for - (a) pure [OMIm]Tf ${ }_{2} \mathrm{~N}$ on copper, (b) [OMIm] Tf $f_{2} \mathrm{~N}$ deposited on a lithium layer, (c) lithium deposited on a [OMIm]Tf $f_{2} \mathrm{~N}$ layer, (d) $[\mathrm{OM} / \mathrm{m}] \mathrm{Tf}_{2} \mathrm{~N}$ deposited on $\mathrm{Li}_{2} \mathrm{O}$.

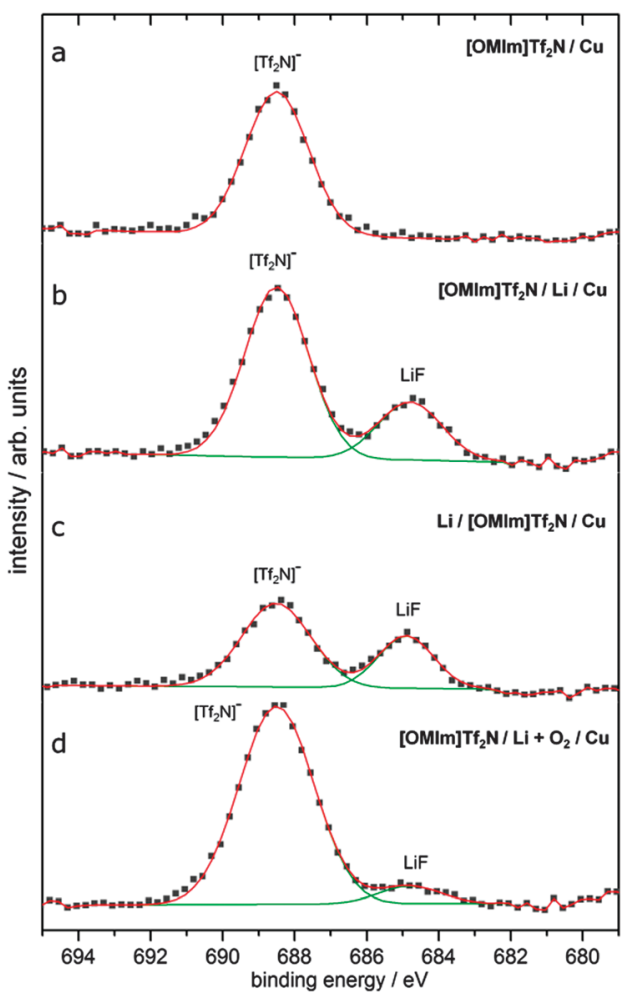

Fig. 4 F 1s XPS spectra for - (a) pure [OMIm]Tf $f_{2} \mathrm{~N}$ on copper, (b) [OMIm]Tf $f_{2} \mathrm{~N}$ deposited on a lithium layer, (c) lithium deposited on a [OMIm] $\mathrm{Tf}_{2} \mathrm{~N}$ layer, (d) $[\mathrm{OMIm}] \mathrm{Tf}_{2} \mathrm{~N}$ deposited on $\mathrm{Li}_{2} \mathrm{O}$.

\section{2. $[\mathrm{OMIm}] \mathrm{Tf}_{2} \mathrm{~N} / \mathrm{Li} / \mathrm{Cu}$}

When $[\mathrm{OMIm}] \mathrm{Tf}_{2} \mathrm{~N}$ is deposited on a lithium layer major changes can be observed for the cation components in the $\mathrm{C}$ 1s (Fig. 1b) and $\mathrm{N} 1 \mathrm{~s}$ region (Fig. $2 \mathrm{~b}$ ).

The C 1s peaks of the cation lose about $84 \%$ of their peak area and both shift by approx. $0.5 \mathrm{eV}$ to lower binding energies to $285.9 \mathrm{eV}$ and $284.5 \mathrm{eV}$. In contrast the peak area of the anion peak in the $\mathrm{C} 1 \mathrm{~s}$ region at $292.7 \mathrm{eV}$ does not significantly change.

At $281.7 \mathrm{eV}$ a new component shows up in the region where we would expect carbon bound to lithium. The lithium seems to have reacted with the carbon either in the imidazolium ring or in the aliphatic chain to build $\mathrm{Li}_{x} \mathrm{CH}_{y}$. The peak assignment to $\mathrm{Li}_{x} \mathrm{CH}_{y}$ is in good agreement with the lithium carbon bounds observed for powdered methyllithium and dilithiomethane samples by Meyers et $a l .^{32}$

In the $\mathrm{N} 1 \mathrm{~s}$ region the cation component at $401.8 \mathrm{eV}$ has vanished completely, while the anion component still is located at $399.3 \mathrm{eV}$. Additionally a new component is detected at $397.4 \mathrm{eV}$, which is difficult to allocate without doubt as it could either be related to decomposed $[\mathrm{OMIm}]^{+}$cations or decomposed $\left[\mathrm{Tf}_{2} \mathrm{~N}\right]^{-}$ anions. However, this peak most likely originates from nitrogen in $[\mathrm{OMIm}]^{+}$shifted by $4.4 \mathrm{eV}$ to lower binding energies. This means the nitrogen is under these conditions in a completely different chemical environment compared to nitrogen in the imidazolium ring and thus the cation character of [OMIm] $]^{+}$is lost during the interaction with $\mathrm{Li}$.

The $\left[\mathrm{Tf}_{2} \mathrm{~N}\right]^{-}$peak in the $\mathrm{O} 1 \mathrm{~s}$ region (Fig. 3b) exhibits a shoulder peak on the low binding energy side at $531.2 \mathrm{eV}$ which is related to reaction products of lithium and [OMIm] $\mathrm{Tf}_{2} \mathrm{~N}$. In this region of $\mathrm{O} 1 \mathrm{~s}$ we expect $\mathrm{Li}_{2} \mathrm{CO}_{3}$, but as well $\mathrm{LiOH}$ like shown in XPS studies at the electrode surface of non ionic liquid based lithium ion batteries. ${ }^{33,34}$

Additionally a new peak appears at $528.1 \mathrm{eV}$ with a peak area of 16 at $\%$ of the total $\mathrm{O} 1 \mathrm{~s}$ area, which can be assigned to oxygen in $\mathrm{Li}_{2} \mathrm{O} .{ }^{33-35}$

The F 1s spectrum in Fig. $4 \mathrm{~b}$ also shows a new component at $684.8 \mathrm{eV}$ referring to $\mathrm{LiF}^{36}$

We can conclude that both anion and cation react with the lithium layer. As these reactions might be influenced by beam damage under the incidence of X-ray radiation, we did time dependent measurements. Fig. 5 and 6 display time resolved XPS spectra of the F 1s and C 1s region in a waterfall plot. For reasons of clarity and comparability the first recorded spectrum is fitted and displayed like the spectra in Fig. 1-4, while the other ones are displayed as solid line. For a more detailed view the area of each peak fit is plot in relation to the measurement time in ESI $\dagger$ (Fig. S2).

Fig. 5 clearly shows a continuous decay of the $\mathrm{F} 1 \mathrm{~s}$ anion peak at $688.5 \mathrm{eV}$ while the $\mathrm{F} 1 \mathrm{~s}$ peak of $\mathrm{LiF}$ at $684.8 \mathrm{eV}$ increases. Thus the LiF forms because of beam damage on the anion side. However, as it is already present at the moment where the measurement starts we have to conclude that the initial presence of $\mathrm{LiF}$ is due to the reaction of the IL layer with lithium.

The anion peak in the C 1s spectrum (Fig. 6) at $292.7 \mathrm{eV}$ is in good agreement with this. While its peak area continuously decays 


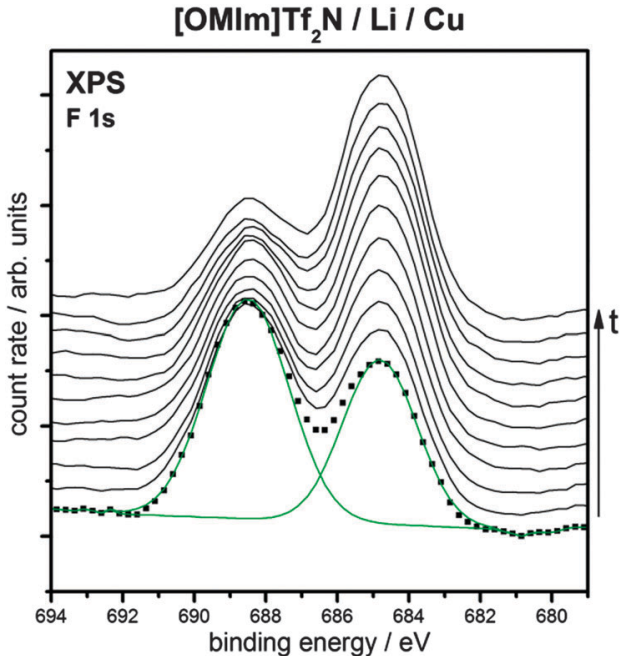

Fig. 5 Waterfall plot of $\mathrm{F}$ 1s XPS spectra for $[\mathrm{OMIm}] \mathrm{Tf}_{2} \mathrm{~N}$ deposited on lithium with rising measurement time.

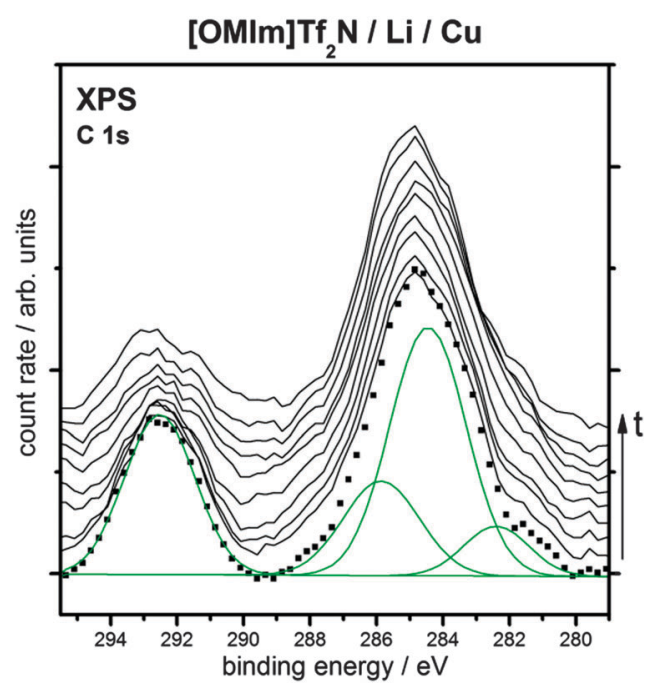

Fig. 6 Waterfall plot of $\mathrm{C}$ 1s XPS spectra for $[\mathrm{OMIm}] \mathrm{Tf}_{2} \mathrm{~N}$ deposited on lithium with rising measurement time.

no significant change can be seen for the cation peaks at $285.9 \mathrm{eV}$ and $284.5 \mathrm{eV}$, as well as for the $\mathrm{Li}_{x} \mathrm{CH}_{y}$ component. Even the $\mathrm{N} 1 \mathrm{~s}$ spectrum (see ESI $\dagger$ ) does not change with time of measurement. This means the cation reaction must have taken place before the XPS analysis started and the decomposition is not induced by the XPS measurements.

Comparing the $\mathrm{C}$ 1s and $\mathrm{F}$ 1s spectra in Fig. 5 and 6 with the ones in Fig. $1 \mathrm{~b}$ and $4 \mathrm{~b}$ the anion seems to be more strongly reacting with the lithium surface in the waterfall plots (small intensity in the $\mathrm{C} 1 \mathrm{~s}$ anion component, great amount of LiF). This most likely is related to the changed order of measurement, may as well be due to partially oxidation of the lithium surface before evaporating $[\mathrm{OMIm}] \mathrm{Tf}_{2} \mathrm{~N}$.

\section{3. $\mathrm{Li} /[\mathrm{OMIm}] \mathrm{Tf}_{2} \mathrm{~N} / \mathrm{Cu}$}

When evaporating lithium on a $[\mathrm{OMIm}] \mathrm{Tf}_{2} \mathrm{~N}$ layer the reaction products are quite similar to those observed before. Major differences were observed for the $\mathrm{C}$ 1s region in Fig. 1c. The anion peak at $292.6 \mathrm{eV}$ has broadened and is much smaller compared to the peak in step 2 (Fig. 1b). However the relative amount of the anion component in $\mathrm{C} 1 \mathrm{~s}$ is still high, compared to the $[\mathrm{OMIm}] \mathrm{Tf}_{2} \mathrm{~N}$ spectrum in the reference (Fig. 1a). The main difference can be detected in the $\mathrm{C} 1 \mathrm{~s}$ cation peaks as the component at $285.9 \mathrm{eV}$, assigned to $\mathrm{C}-\mathrm{N}$, raised compared to the result in step 2 (Fig. 1b), thus even exceeds the amount of the $\mathrm{C}-\mathrm{C}$ component. Maybe this is due to the formation of $\mathrm{C}-\mathrm{O}$ contributions, which would not be distinguishable from $\mathrm{C}-\mathrm{N}$ bonds in the shown $\mathrm{C}$ 1s XPS spectrum.

The shoulder on the low binding energy side of the $\mathrm{C} 1 \mathrm{~s}$ cation peak indicates the existence of $\mathrm{Li}_{x} \mathrm{CH}_{y}$ (ref. 29) and can be fit by a peak at $282.4 \mathrm{eV}$ with an area of 7 at\% of the total peak area of the $\mathrm{C} 1 \mathrm{~s}$ region.

The $\mathrm{N}$ 1s spectrum in Fig. $2 \mathrm{c}$ is in good agreement with the results of [OMIm] $\mathrm{Tf}_{2} \mathrm{~N}$ deposited on a lithium layer shown in step 2 (Fig. 2b). The anion peak can be detected at $399.3 \mathrm{eV}$, while there is a component at $397.3 \mathrm{eV}$ again, which might be related to reaction products of [OMIm] $]^{+}$and lithium.

Small changes are observed for the anion peaks of the $\mathrm{O} 1 \mathrm{~s}$ and $\mathrm{F}$ 1s spectra. The $\mathrm{O} 1 \mathrm{~s}$ spectrum in Fig. 3c shows a shoulder peak at $531.2 \mathrm{eV}$ next to the $\left[\mathrm{Tf}_{2} \mathrm{~N}\right]^{-}$peak at $532.4 \mathrm{eV}$, like observed before in step 2. At $528.5 \mathrm{eV}$ a new component has built, which might be $\mathrm{Li}_{2} \mathrm{O}$ shifted $0.4 \mathrm{eV}$ to higher binding energies. Compared to [OMIm] $\mathrm{Tf}_{2} \mathrm{~N}$ evaporated on a lithium layer (step 2) the total intensity of the $\mathrm{O} 1$ s anion peak decreased.

A similar trend is observed at the anion peak in the $\mathrm{F} 1 \mathrm{~s}$ region in Fig. 4c as its peak area decreased compared to the spectrum in step 2. The area of the LiF component of $\mathrm{F} 1 \mathrm{~s}$ at $684.9 \mathrm{eV}$ increased to $33 \%$ of the whole $\mathrm{F} 1 \mathrm{~s}$ peak area.

\section{4. $[\mathrm{OMIm}] \mathrm{Tf}_{2} \mathrm{~N} / \mathrm{Li}_{2} \mathrm{O} / \mathrm{Cu}$}

The formation of $\mathrm{Li}_{2} \mathrm{O}$ surfaces by an interaction of oxygen with a lithium multilayer has been investigated by Shek et al. ${ }^{37}$ Referring to their work a lithium layer was oxidized by exposure of approx. $10 \mathrm{~L} \mathrm{O}_{2}$. The formation of a $\mathrm{Li}_{2} \mathrm{O}$ surface has been verified by UPS spectra and XPS analysis of the $\mathrm{O} 1 \mathrm{~s}$ peak. Next to the $\mathrm{Li}_{2} \mathrm{O}$ peak the $\mathrm{O} 1 \mathrm{~s}$ spectrum after $\mathrm{O}_{2}$ exposure exhibits a smaller peak, which may be associated with partial oxidation of the copper surface. Thus the lithium layer might either not be completely closed or there is oxygen diffusion through the lithium layer.

As for the results shown above in step 2 and step 3 (Fig. 1b and $\mathrm{c}$ ), the $\mathrm{C} 1 \mathrm{~s}$ component of the anion in Fig. 1d is intense compared to the cation peaks. However, the [OMIm] ${ }^{+}$peak with its components at $284.5 \mathrm{eV}$ and $285.9 \mathrm{eV}$ is shaped like the reference peak in step 1 (Fig. 1a). Additionally there is a small component at $283.1 \mathrm{eV} \mathrm{BE}$ which is correlated to $\mathrm{Li}_{x} \mathrm{CH}_{y}{ }^{32}$ like already observed for the previous experiments. The small shoulder peak in the $\mathrm{C} 1 \mathrm{~s}$ spectrum at $287.1 \mathrm{eV}$ on the high binding energy side of the cation peak could be explained by $\mathrm{C}-\mathrm{F}$ fragments of decomposed anion.

In Fig. $2 \mathrm{~d}$ the $\mathrm{N} 1 \mathrm{~s}$ spectrum of $[\mathrm{OMIm}] \mathrm{Tf}_{2} \mathrm{~N}$ evaporated on an oxidized lithium layer is shown. There are three peaks visible in the $\mathrm{N}$ 1s region. The peaks at $397.4 \mathrm{eV}$ and $399.3 \mathrm{eV}$ are in 
good agreement with the components shown in step 2 and step 3 (Fig. 2b and c). Compared to them the peak area and thus the amount of nitrogen of the new component at $397.4 \mathrm{eV}$ is decreased.

Additionally there is another component at $401.0 \mathrm{eV}$ which most probably is related to nitrogen in [OMIm] $]^{+}$. The shift of the $\mathrm{N} 1 \mathrm{~s}$ peak by $0.8 \mathrm{eV}$ to lower binding energies, compared to the $[\mathrm{OMIm}]^{+}$component in the reference, can be explained by a slightly modified chemical environment and is in good agreement with XPS spectra of neutral imidazolium compared to cationic ones ${ }^{38}$ and spectra of RT-ILs with imidazolium cations in general. ${ }^{26,29}$

When [OMIm] $\mathrm{Tf}_{2} \mathrm{~N}$ is deposited on top of the $\mathrm{Li}_{2} \mathrm{O}$ layer the $\mathrm{O}$ 1s spectrum (Fig. 3d) shows 4 different peaks. On the one hand the peaks of $\mathrm{Li}_{2} \mathrm{O}$ at $528.1 \mathrm{eV}$ and $\mathrm{Cu}_{x} \mathrm{O}$ at $530.5 \mathrm{eV}$, which already have been measured before evaporating [OMIm] $\mathrm{Tf}_{2} \mathrm{~N}$, on the other hand the $\mathrm{O} 1 \mathrm{~s}$ peak of $\left[\mathrm{Tf}_{2} \mathrm{~N}\right]^{-}$at $532.4 \mathrm{eV}$ and the shoulder peak at $531.2 \mathrm{eV}$, which both can be fit analog to steps 2 and 3 (see Fig. $3 \mathrm{~b}$ and c). Remarkably the shoulder peak has $17 \%$ of the whole $\mathrm{O} 1 \mathrm{~s}$ peak area, thus $\mathrm{Li}_{2} \mathrm{O}$ might be reduced in the reaction with $[\mathrm{OMIm}] \mathrm{Tf}_{2} \mathrm{~N}$.

In contrast the $\mathrm{F}$ 1s spectrum in Fig. $4 \mathrm{~d}$ is clearly dominated by the fluorine in the $\mathrm{CF}_{3}$ component of the anion. The LiF component at $684.8 \mathrm{eV}$ is quite small with a peak area of $7 \%$ of the sum of both $\mathrm{F}$ 1s component areas.

Li 1s. For each of the experiments $\mathrm{Li} 1 \mathrm{~s}$ can be detected in the region between $54 \mathrm{eV}$ and $58 \mathrm{eV}$. The resulting Li 1s spectra after reaction of lithium and [OMIm] $\mathrm{Tf}_{2} \mathrm{~N}$ are shown in Fig. 7. Due to the very low photoionization cross section of the Li $1 \mathrm{~s}$ state, long integration times have to be chosen to observe this peak in more detail. As this would enhance the decomposition

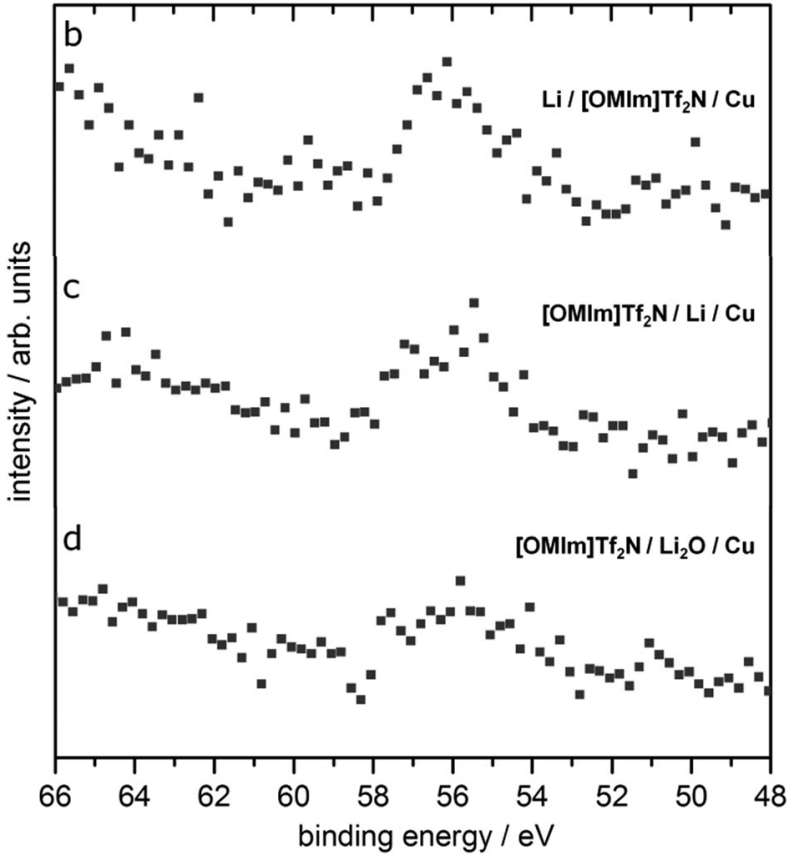

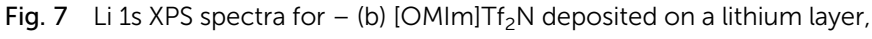
(c) lithium deposited on a [OMIm] Tf ${ }_{2} \mathrm{~N}$ layer, (d) $\left[\mathrm{OMIm}^{2} \mathrm{Tf}_{2} \mathrm{~N}\right.$ deposited on $\mathrm{Li}_{2} \mathrm{O}$. of the ionic liquid and possibly lead to side reactions, a bad signal/noise ratio has to be taken into account here.

UPS results. In addition to the XPS results UPS spectra were recorded (see ESI $\dagger$ ) for [OMIm] $\mathrm{Tf}_{2} \mathrm{~N}$ deposited on $\mathrm{Li}$ and on $\mathrm{Li}_{2} \mathrm{O}$ immediately after sample preparation. With increasing time after deposition the two main peaks of the RT- $\mathrm{IL}^{30,39}$ decrease continuously, which could be caused by desorption of the ionic liquid or by rearrangement of the components and has not been observed before. ${ }^{20}$ Further experiments are needed to interpret these UPS results in detail. In the case of [OMIm] $\mathrm{Tf}_{2} \mathrm{~N}$ evaporated on top of the lithium layer contributions of $\mathrm{LiF}$ and $\mathrm{Li}_{2} \mathrm{O}$ appear next to the main peaks of the RT-IL, which is in good agreement with the XPS results. When evaporated on top of the oxidized lithium layer no additional features can be observed next to a small $\mathrm{Li}_{2} \mathrm{O}$ peak and the main peaks of $[\mathrm{OMIm}] \mathrm{Tf}_{2} \mathrm{~N}$.

\section{Discussion}

The experiments exhibit an instability of [OMIm] $\mathrm{Tf}_{2} \mathrm{~N}$ against lithium. As shown in the time-resolved XPS spectra in Fig. 5 and 6 some of the species observed formed during the measurement, i.e. caused by the incidence of $\mathrm{X}$-rays.

A fragmentation of the $\left[\mathrm{Tf}_{2} \mathrm{~N}\right]^{-}$anion by electrons was shown in literature before. ${ }^{40,41}$ Whishart et al. observed the degradation pathways of different ILs by electron paramagnetic resonance spectroscopy and predicted a charge transfer process of the much more stable cation radicals to the anion. ${ }^{40}$ Keppler et al. have shown similar anion fragmentation and desorption occurring on slow time-scales when exposed to X-ray radiation, which most probably is the reason for the formation of $\mathrm{LiF}$ and $\mathrm{Li}_{2} \mathrm{O}$ during the measurements in the presence of lithium. ${ }^{16}$

However, as the time-resolved XPS spectra in Fig. 5 exhibit a certain amount of $\mathrm{LiF}$ even in the first spectrum, the reactions of $\left[\mathrm{Tf}_{2} \mathrm{~N}\right]$ and lithium initially started before XPS analysis. This is in good agreement with the few observations on lithium ion batteries using ionic liquids with $\left[\mathrm{Tf}_{2} \mathrm{~N}\right]^{-}$anion as electrolyte. ${ }^{42,43}$

\section{$\left[\mathrm{C}_{\mathbf{4}} \mathrm{C}_{\mathbf{1}}\right.$ Pyrr $] \mathrm{Tf}_{\mathbf{2}} \mathrm{N}$}

The decomposition of the cation in the presence of lithium is subject to a different process, as the cation peaks of the $\mathrm{N} 1 \mathrm{~s}$ and $\mathrm{C}$ 1s regions do not change during XPS analysis. To investigate the role of the imidazolium cation in the reaction, experiments with ionic liquids with alternative cations have to be performed and compared to these results.

As a first insight Fig. 8 and 9 show the $\mathrm{C} 1 \mathrm{~s}$ and $\mathrm{N} 1 \mathrm{~s}$ spectra of $\left[\mathrm{C}_{4} \mathrm{C}_{1}\right.$ Pyrr $\mathrm{Tf}_{2} \mathrm{~N}$ (1-butyl-1-methylpyrrolidinium bis[trifluoromethylsulfonyl]amide) deposited on copper and on lithium/ copper, similar to the experiments above. The XPS spectra of ionic liquids with pyrrolidinium ions have been well described by Men et al. ${ }^{44}$ As those spectra are in good agreement with the present results interactions of $\left[\mathrm{C}_{4} \mathrm{C}_{1} \mathrm{Pyrr}\right] \mathrm{Tf}_{2} \mathrm{~N}$ with copper, recently observed for sub-monolayers, ${ }^{28}$ might have a minor effect on thicker RT-IL films.

Due to the different chemical environment of carbon bound to nitrogen the carbon in the cation $\mathrm{C}$ 1s spectrum in Fig. 8 can 


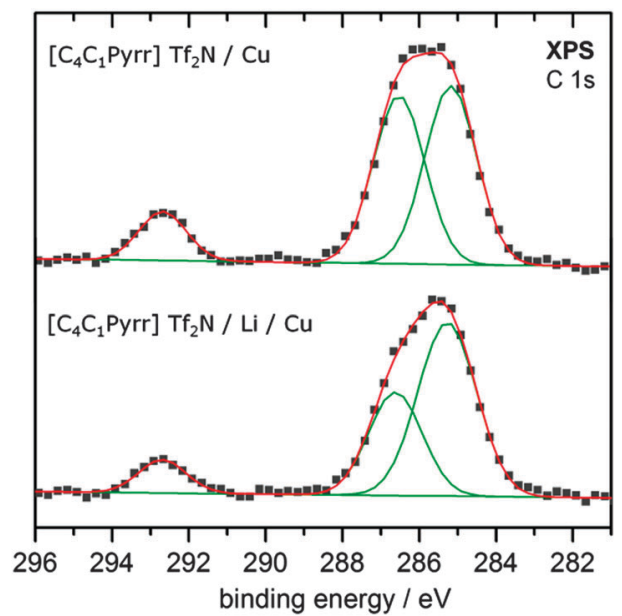

Fig. $8 \quad C$ 1s XPS spectra for $\left[C_{4} C_{1}\right.$ Pyrr $] T f_{2} N$ deposited on copper (top) and on a lithium layer (bottom).

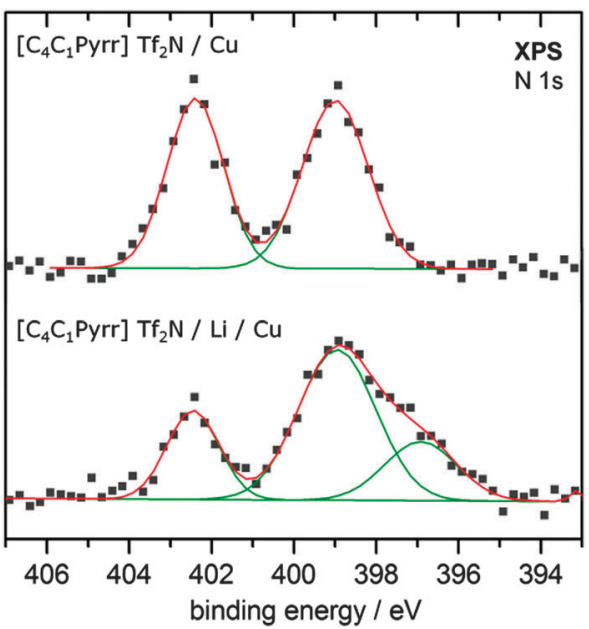

Fig. 9 N1s XPS spectra for $\left[C_{4} C_{1}\right.$ Pyrr $] T f_{2} N$ deposited on copper (top) and on a lithium layer (bottom)

be divided in $\mathrm{C}-\mathrm{C}$ and $\mathrm{C}-\mathrm{N}$ components, too. If $\left[\mathrm{C}_{4} \mathrm{C}_{1}\right.$ Pyrr $] \mathrm{Tf}_{2} \mathrm{~N}$ is evaporated on lithium, the intensity of the second peak (here at $286.5 \mathrm{eV}$ ) associated with carbon in a nitrogen electronic environment decreases, while the peak area of the other components remains nearly constant. The peak area of the $\mathrm{N} 1 \mathrm{~s}$ cation peak (at $402.4 \mathrm{eV}$ ) in Fig. 9 decreases when the RT-IL is evaporated on lithium, in good agreement to the $\mathrm{C} 1 \mathrm{~s}$ spectra. Additionally a new component has formed at $396.9 \mathrm{eV}$ analog to the results observed for $\mathrm{N}$ 1s in [OMIm] $\mathrm{Tf}_{2} \mathrm{~N}$ (see Fig. 2).

Howlett et al. analysed the solid electrolyte interface of a cycled lithium/copper electrode using $\left[\mathrm{C}_{4} \mathrm{C}_{1} \mathrm{Pyrr}\right] \mathrm{Tf}_{2} \mathrm{~N}$ as electrolyte. ${ }^{42}$ They observed the presence of reduction products of $\left[\mathrm{Tf}_{2} \mathrm{~N}\right]^{-}$ on the electrode interface, in good agreement with the anion reaction products shown before. Although a certain influence of the cation was noted, the role of $\left[\mathrm{C}_{4} \mathrm{C}_{1} \mathrm{Pyrr}\right]^{+}$in the reaction remains ambiguous. Interestingly also a new component in the $\mathrm{N}$ 1s XPS spectrum was found on the low binding energy side after interaction with lithium, which is supposed to be nitride and part of the native film of the ex situ prepared sample.

In our case no nitrogen contamination was observed during sample preparation (see survey spectra in ESI $\dagger$ ). On the contrary Fig. 9 shows the formation of a new nitrogen species concomitant with partially decomposition of $\left[\mathrm{C}_{4} \mathrm{C}_{1} \mathrm{Pyrr}\right]^{+}$. This most likely is based on a breakup of the pyrrolidinium structure changing the local chemical environment of nitrogen to a chain-like $\mathrm{LiC}_{x} \mathrm{H}_{y} \mathrm{~N}$ structure.

Nguyen et al. investigated the SEI during lithiation of a siliconcopper electrode covered with $\left[\mathrm{C}_{3} \mathrm{C}_{1}\right.$ Pyrr $] \mathrm{Tf}_{2} \mathrm{~N}$ using FTIR spectroscopy and XPS. ${ }^{45}$ They observed degradation of anion and cation depending on the applied voltage and cleavage of $\mathrm{C}-\mathrm{F}$ bonds in the $\left[\mathrm{Tf}_{2} \mathrm{~N}\right]^{-}$anion responsible for LiF formation. In the $\mathrm{N} 1 \mathrm{~s}$ region of the XPS results a new peak is detected with a similar binding energy shift, which is supposed to be related with further degradation products of the anion after cleavage of the $\mathrm{C}-\mathrm{F}$ bond.

On the contrary Weingarth et al. performed an in situ

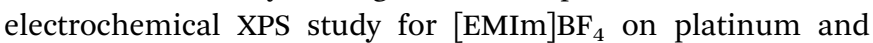
observed the formation of a new peak at this position in the $\mathrm{N}$ 1s region, which is a clear evidence for an imidazolium cation decomposed and fragments adsorbed on the electrode surface. ${ }^{46}$

As $\mathrm{N}$ 1s spectra of $\left[\mathrm{C}_{4} \mathrm{C}_{1} \mathrm{Pyrr}\right] \mathrm{Tf}_{2} \mathrm{~N}$ and [OMIm] $\mathrm{Tf}_{2} \mathrm{~N}$, each in interaction with lithium, show similarities concerning the cation region (compare with Fig. 2b-d), breakup of the imidazolium structure most probably is the reason for the changes of the cation peaks in steps $2-4$, too. But as both decomposed $\mathrm{Tf}_{2} \mathrm{~N}$ anions ${ }^{45}$ and decomposed imidazolium cations ${ }^{46}$ result in an $\mathrm{N}$ 1s component around $397.4 \mathrm{eV}$ this cannot be proven here.

Nevertheless, quite similar results with XPS have been obtained for tetrahydrofuran and propylene carbonate by Zhuang. et al. ${ }^{15}$ Both organic molecules react with the lithium layer and were decomposed. The authors claim the decomposition is based on ring-opening, too. In addition they found desorption of fragments of the decomposed molecules into the vacuum at elevated temperatures.

Furthermore Zhao et al. observed changes in the XPS cation peaks of [EMIm] $\mathrm{Tf}_{2} \mathrm{~N}$, which is used as electrolyte for lithium secondary batteries, after cycling. Those changes as well were reported to involve breakup of the imidazolium ring and are quite similar to the present results. ${ }^{47}$

For a slight impression of the mechanisms behind Valencia et al. performed $a b$ initio calculations of [EMIm] $\mathrm{BF}_{4}$ adsorbed on crystalline lithium surfaces. ${ }^{48}$ They observed a great attraction of lithium to the $\left[\mathrm{BF}_{4}\right]^{-}$anion together with the partial reduction of [EMIm] $]^{+}$.

But as $\mathrm{Li}_{x} \mathrm{CH}_{\mathrm{y}}$ components and most probably $\mathrm{C}-\mathrm{O}$ compounds can be observed in the results here, the decomposition of $[\mathrm{OMIm}]^{+}$cation might be more complex and proceeding in several steps. Especially the differences in the cation components of the $\mathrm{C} 1 \mathrm{~s}$ spectra (Fig. 1) of [OMIm] $\mathrm{Tf}_{2} \mathrm{~N}$ deposited on lithium and lithium deposited on a [OMIm] $\mathrm{Tf}_{2} \mathrm{~N}$ layer are unclear at this state. As the intensity and peak area ratio of the $\mathrm{N}$ 1s peaks (Fig. 2) of both experiments are in good agreement, carbon species of decomposed [OMIm] $]^{+}$most likely were involved in the reaction with lithium. This furthermore would 
explain the shoulder peak in the $\mathrm{O} 1$ s spectrum, which could not be explained by anion decomposition. However the peaks would not be distinguishable from the peaks of [OMIm] $\mathrm{Tf}_{2} \mathrm{~N}$ in the $\mathrm{C} 1 \mathrm{~s}$ and $\mathrm{O} 1 \mathrm{~s}$ spectra, thus further experiments are needed.

The results of the UPS spectra indicate a loss of [OMIm] $\mathrm{Tf}_{2} \mathrm{~N}$ or its components in the interaction with lithium or $\mathrm{Li}_{2} \mathrm{O}$ (see ESI $\dagger$ ). This is emphasized by loss of intensity in the XPS peaks, mainly in $\mathrm{C}$ 1s cation peaks, and supports the conclusion most of the cations or more likely parts of decomposed cations were desorbed in presence of lithium on the copper surface.

As loss of fragments from X-ray induced degraded imidazolium cations using mass spectroscopy has been observed before $^{16}$ thermal desorption spectroscopy (TDS) measurements of ionic liquids on a lithium surface could help out identifying desorbed species and thus might explain the decomposition of $[\mathrm{OMIm}]^{+}$in presence of lithium in more detail.

Passivation of the lithium surface slows down or even prevents the interaction of [OMIm] $\mathrm{Tf}_{2} \mathrm{~N}$ and lithium. This is obvious comparing the peak area of the LiF species in the F 1s spectra (Fig. 4b-d). The highest amount of LiF with $33 \%$ can be found for lithium deposited on top of [OMIm] $\mathrm{Tf}_{2} \mathrm{~N}$. The amount of $\mathrm{LiF}$ when [OMIm] $\mathrm{Tf}_{2} \mathrm{~N}$ is deposited on a previously oxidized lithium layer is only $7 \%$ of the total $\mathrm{F} 1 \mathrm{~s}$ peak area. In this case even the cation does not decompose completely. When lithium is evaporated first followed by evaporation of [OMIm] $\mathrm{Tf}_{2} \mathrm{~N}$ there might be a passivation of the lithium surface by the reaction products leading to a lower amount of $\mathrm{LiF}$ and $\mathrm{Li}_{2} \mathrm{O}$.

\section{Conclusion}

In the current paper the reaction of the ionic liquid [OMIm] $\mathrm{Tf}_{2} \mathrm{~N}$ with $\mathrm{Li}$ and $\mathrm{Li}_{2} \mathrm{O}$ has been investigated. Both the cation and the anion react with lithium, giving a series of decomposition products like $\mathrm{Li}_{x} \mathrm{CH}_{y}, \mathrm{Li}_{2} \mathrm{O}$ and $\mathrm{LiF}$. Time resolved XPS measurements show that species like $\mathrm{LiF}$ and $\mathrm{Li}_{2} \mathrm{O}$ continuously form during the measurement. However, as these species were already present at the moment where the XPS measurement has started it is excluded that they solely form during the measurement, thus they must initially be the result of a chemical reaction of [OMIm] $]^{+}$ with lithium. Interestingly, the cation $\mathrm{C} 1 \mathrm{~s}$ and $\mathrm{N}$ 1s spectra show similarities when compared to the first results obtained for the interaction of $\left[\mathrm{C}_{4} \mathrm{C}_{1}\right.$ Pyrr $] \mathrm{Tf}_{2} \mathrm{~N}$ with lithium.

The results give a first insight into the reaction products that have to be expected when [OMIm] $\mathrm{Tf}_{2} \mathrm{~N}$ and other ionic liquids with an imidazolium cation shall be used either as electrolyte or additive in lithium ion batteries. In our next steps we will thus investigate how liquids with pyrrolidinium cations interact with lithium or sodium in more detail.

\section{Acknowledgements}

This work was supported within the post graduate programme "Graduiertenkolleg Energiespeicher und Elektromobilität Niedersachsen” (GEENI) by the Federal Ministry of Science and Culture in Lower Saxony.

\section{References}

1 K. Binnemans, Chem. Rev., 2005, 105, 4148-4204.

2 F. Endres and S. Zein El Abedin, Phys. Chem. Chem. Phys., 2006, 8, 2101.

3 C. Pinilla, M. G. Del Pópolo, R. M. Lynden-Bell and J. Kohanoff, J. Phys. Chem. B, 2005, 109, 17922-17927.

4 K. Kanai, T. Nishi, T. Iwahashi, Y. Ouchi, K. Seki, Y. Harada and S. Shin, J. Electron. Spectrosc. Relat. Phenom., 2009, 174, 110-115.

5 V. Lockett, R. Sedev, C. Bassell and J. Ralston, Phys. Chem. Chem. Phys., 2008, 10, 1330.

6 D. Yoshimura, T. Yokoyama, T. Nishi, H. Ishii, R. Ozawa, H. Hamaguchi and K. Seki, J. Electron. Spectrosc. Relat. Phenom., 2005, 144-147, 319-322.

7 D. Ensling, M. Stjerndahl, A. Nytén, T. Gustafsson and J. O. Thomas, J. Mater. Chem., 2008, 19, 82.

8 H. Sakaebe and H. Matsumoto, Electrochem. Commun., 2003, 5, 594-598.

9 M. Ishikawa, T. Sugimoto, M. Kikuta, E. Ishiko and M. Kono, J. Power Sources, 2006, 162, 658-662.

10 H. Sakaebe, H. Matsumoto and K. Tatsumi, J. Power Sources, 2005, 146, 693-697.

11 H. Matsumoto, H. Sakaebe, K. Tatsumi, M. Kikuta, E. Ishiko and M. Kono, J. Power Sources, 2006, 160, 1308-1313.

12 F. F. Bazito, Y. Kawano and R. M. Torresi, Electrochim. Acta, 2007, 52, 6427-6437.

13 M. Armand, F. Endres, D. R. MacFarlane, H. Ohno and B. Scrosati, Nat. Mater., 2009, 8, 621-629.

14 A. Lewandowski and A. Świderska-Mocek, J. Power Sources, 2009, 194, 601-609.

15 G. Zhuang, K. Wang and P. N. Ross, Surf. Sci., 1997, 387, 199-212.

16 A. Keppler, M. Himmerlich, T. Ikari, M. Marschewski, E. Pachomow, O. Höfft, W. Maus-Friedrichs, F. Endres and S. Krischok, Phys. Chem. Chem. Phys., 2010, 13, 1174.

17 J. Shu, M. Shui, F. Huang, D. Xu, Y. Ren, L. Hou, J. Cui and J. Xu, Electrochim. Acta, 2011, 56, 3006-3014.

18 M. Bowker and R. J. Madix, Surf. Sci., 1981, 102, 542-565.

19 T. Cremer, M. Stark, A. Deyko, H.-P. Steinrück and F. Maier, Langmuir, 2011, 27, 3662-3671.

20 S. Krischok, A. Ulbrich, T. Ikari, V. Kempter, M. Marschewski and O. Höfft, Nucl. Instrum. Methods Phys. Res., Sect. B, 2014, DOI: 10.1016/j.nimb.2014.07.036.

21 S. Zhang, N. Sun, X. He, X. Lu and X. Zhang, J. Phys. Chem. Ref. Data, 2006, 35, 1475.

22 D. Shirley, Phys. Rev. B: Solid State, 1972, 5, 4709-4714.

23 J. H. Scofield, J. Electron. Spectrosc. Relat. Phenom., 1976, 8, 129-137.

24 J. J. Yeh and I. Lindau, At. Data Nucl. Data Tables, 1985, 32, 1-155.

25 R. F. Roberts, D. L. Allara, C. A. Pryde, D. N. E. Buchanan and N. D. Hobbins, Surf. Interface Anal., 1980, 2, 5-10.

26 K. R. J. Lovelock, I. J. Villar-Garcia, F. Maier, H.-P. Steinrück and P. Licence, Chem. Rev., 2010, 110, 5158-5190. 
27 C. Cardinaud, J. Electrochem. Soc., 1988, 135, 1472.

28 B. Uhl, F. Buchner, S. Gabler, M. Bozorgchenani and R. Jürgen Behm, Chem. Commun., 2014, 50, 8601-8604.

29 H.-P. Steinrück, Phys. Chem. Chem. Phys., 2012, 14, 5010.

30 T. Ikari, A. Keppler, M. Reinmöller, W. J. D. Beenken, S. Krischok, M. Marschewski, W. Maus-Friedrichs, O. Höfft and F. Endres, e-J. Surf. Sci. Nanotechnol., 2010, 8, 241-245.

31 M. Reinmöller, A. Ulbrich, T. Ikari, J. Preiß, O. Höfft, F. Endres, S. Krischok and W. J. D. Beenken, Phys. Chem. Chem. Phys., 2011, 13, 19526.

32 G. F. Meyers, M. B. Hall, J. W. Chinn and R. J. Lagow, J. Am. Chem. Soc., 1985, 107, 1413-1414.

33 Q.-H. Wu, A. Thißen and W. Jaegermann, Surf. Sci., 2005, 578, 203-212.

34 C. K. Chan, R. Ruffo, S. S. Hong and Y. Cui, J. Power Sources, 2009, 189, 1132-1140.

35 R. Younesi, S. Urbonaite, K. Edström and M. Hahlin, J. Phys. Chem. C, 2012, 116, 20673-20680.

36 S. Kowalczyk, F. McFeely, L. Ley, R. Pollak and D. Shirley, Phys. Rev. B: Solid State, 1974, 9, 3573-3581.

37 M. L. Shek, J. Hrbek, T. K. Sham and G.-Q. Xu, Surf. Sci., 1990, 234, 324-334.
38 D. Nolting, N. Ottosson, M. Faubel, I. V. Hertel and B. Winter, J. Am. Chem. Soc., 2008, 130, 8150-8151.

39 O. Höfft, S. Bahr, M. Himmerlich, S. Krischok, J. A. Schaefer and V. Kempter, Langmuir, 2006, 22, 7120-7123.

40 J. F. Wishart, I. A. Shkrob and S. D. Chemerisov, J. Phys. Chem. B, 2007, 111, 11786-11793.

41 G. Chatel, R. Pflieger, E. Naffrechoux, S. I. Nikitenko, J. Suptil, C. Goux-Henry, N. Kardos, B. Andrioletti and M. Draye, ACS Sustainable Chem. Eng., 2013, 1, 137-143.

42 P. C. Howlett, N. Brack, A. F. Hollenkamp, M. Forsyth and D. R. MacFarlane, J. Electrochem. Soc., 2006, 595-606.

43 C. C. Nguyen and S.-W. Song, Electrochem. Commun., 2010, 12, 1593-1595.

44 S. Men, B. B. Hurisso, K. R. J. Lovelock and P. Licence, Phys. Chem. Chem. Phys., 2012, 14, 5229.

45 C. C. Nguyen, S.-W. Woo and S.-W. Song, J. Phys. Chem. C, 2012, 116, 14764-14771.

46 D. Weingarth, A. Foelske-Schmitz, A. Wokaun and R. Kötz, Electrochem. Commun., 2011, 13, 619-622.

47 L. Zhao, J.-i. Yamaki and M. Egashira, J. Power Sources, 2007, 174, 352-358.

48 H. Valencia, M. Kohyama, S. Tanaka and H. Matsumoto, Phys. Rev. B: Condens. Matter Mater. Phys., 2008, 78, 205402. 